University of Nebraska - Lincoln

DigitalCommons@University of Nebraska - Lincoln

Oil-Soluble Dyes Incorporated in Meridic Diet of Diatraea grandiosella (Lepidoptera: Crambidae) as Markers for Adult Dispersal Studies

\author{
Jawwad A. Qureshi \\ Kansas State University \\ L. L. Buschman \\ Kansas State University, Ibuschma@ksu.edu \\ James E. Throne \\ USDA-ARS, Manhattan, KS, james.throne@ars.usda.gov \\ Sonny B. Ramaswamy \\ Kansas State University
}

Follow this and additional works at: https://digitalcommons.unl.edu/usdaarsfacpub

Qureshi, Jawwad A.; Buschman, L. L.; Throne, James E.; and Ramaswamy, Sonny B., "Oil-Soluble Dyes Incorporated in Meridic Diet of Diatraea grandiosella (Lepidoptera: Crambidae) as Markers for Adult Dispersal Studies" (2004). Publications from USDA-ARS / UNL Faculty. 2019.

https://digitalcommons.unl.edu/usdaarsfacpub/2019

This Article is brought to you for free and open access by the U.S. Department of Agriculture: Agricultural Research Service, Lincoln, Nebraska at DigitalCommons@University of Nebraska - Lincoln. It has been accepted for inclusion in Publications from USDA-ARS / UNL Faculty by an authorized administrator of DigitalCommons@University of Nebraska - Lincoln. 


\title{
Oil-Soluble Dyes Incorporated in Meridic Diet of Diatraea grandiosella (Lepidoptera: Crambidae) as Markers for Adult Dispersal Studies
}

\author{
JAWWAD A. QURESHI, ${ }^{1}$ LAWRENT L. BUSCHMAN, ${ }^{2}$ JAMES E. THRONE, ${ }^{3}$ \\ AND SONNY B. RAMASWAMY
}

Department of Entomology, Kansas State University, Manhattan, KS 66506

J. Econ. Entomol. 97(3): 836-845 (2004)

\begin{abstract}
Mark-release-recapture experiments to study insect dispersal require the release of marked insects that can be easily identified among feral conspecifics. Oil-soluble dyes have been used successfully to mark various insect species. Two oil-soluble dyes, Sudan Red 7B (C.I. 26050) and Sudan Blue 670 (C.I. 61554), were added to diet of the southwestern corn borer, Diatraea grandiosella Dyar, and evaluated against an untreated control diet. Survival, diet consumption, larval and pupal weight, development time, fecundity, longevity, and dry weight of the adults were measured. Adults reared on the three diets were also tested for mating success. Some minor effects were observed for southwestern corn borers reared on the marked diets. Eggs, larvae, pupae, and adults were all reliably marked and readily identifiable. Adults retained color for their entire life span. Adults from each diet mated successfully with adults from the other diets. F1 progeny from the different mating combinations survived to the second instar but tended to lose the marker after 3-4 d on untreated diet. Both Sudan Red 7B and Sudan Blue 670 can be used to mark southwestern corn borer adults and thus should be useful for mark-release-recapture dispersal studies. The dyes will also be useful for short-term studies with marked larvae and oviposition behavior.
\end{abstract}

KEY WORDS southwestern corn borer, development, artificial diet, dye markers, mark-releaserecapture

INSECT DISPERSAL HAS IMPORTANT implications in our understanding of various ecological interactions. Recently, information on insect dispersal has become important for resistance management in transgenic crops that have been developed to control certain Lepidoptera. Transgenic crops are expected to exert strong selection for insect resistance to the toxins expressed in transgenic plants. Evolutionary responses of indigenous organisms to genetically engineered crops could rapidly nullify the crops' advantages (Gould 1988). However, the dispersal of susceptible insects between fields can slow the evolution of resistance and enhance sustainability (Ostlie et al. 1997).

Dispersal of insect pests can be examined by conducting mark-release-recapture experiments (Reynolds et al. 1997). In such studies, field-collected (occasionally) or laboratory-reared (more commonly) insects are marked, released, and recaptured in ap-

Mention of trade names or commercial products in this article is solely for the purpose of providing specific information and does not imply recommendation or endorsement by Kansas State University or the U.S. Department of Agriculture.

${ }^{1}$ Current address: Kansas State University Agricultural Research Center-Hays, 1232 240th Ave., Hays, KS 67601-9228.

${ }^{2}$ E-mail: lbuschma@ksu.edu.

${ }^{3}$ USDA-ARS Grain Marketing and Production Research Center, 1515 College Ave., Manhattan, KS 66502. propriate traps. A wide variety of markers can be used in such studies to assess insect population dynamics, dispersal, territoriality, feeding behavior, trophic relationships, and other ecological interactions (Hagler and Jackson 2001). An ideal marker should persist on the insect, not affect the insect's normal biology, and be safe, cost-effective, and easy to use (Southwood 1969, Hagler and Jackson 2001).

Oil-soluble dyes can be used to mark insects internally because they accumulate in the insect fat body. Some Lepidoptera adults may need to be squeezed to reveal the dye in the internal organs (through the intersegmental membranes of the abdomen) because the external scales do not pick up the dye. Oil-soluble dyes have been used to mark insects in the sterile insect release method (Steiner 1965, Schroeder et al. 1974), in area-wide pest management programs (Gast and Landin 1966, Hendricks et al. 1971), and recently, in dispersal studies associated with resistance management programs in transgenic crops (Hunt et al. 2001, Showers et al. 2001, Qureshi 2003). Dyes have been used to mark insects in the following orders: Coleoptera (Gast and Landin 1966, Lloyd et al. 1968, Daum et al. 1969), Lepidoptera (Graham and Mangum 1971, Jones et al. 1975, Ostlie et al. 1984, Ramaswamy et al. 1985, Showers et al. 1989, Hunt et al. 2000), Diptera (Steiner 1965, Schroeder et al. 1974), Isoptera 
(Lai et al. 1983, Grace and Abdallay 1989, Haagsma and Rust 1993), and Hymenoptera (Strand et al. 1990). A key to the success of these programs has been the availability of an inexpensive and reliable mark that can be applied easily to thousands or millions of insects (Hagler and Jackson 2001).

The dyes are usually dissolved in a vegetable oil (cottonseed, corn, etc.) and incorporated in the diet. The use of dyes incorporated in the diet has a key advantage over other marking techniques in that expensive equipment is not needed to identify marked insects. However, for some dyes and some insects, the specimen may need to be crushed (Coppedge et al. 1979, Showers et al. 1989) or liquified in a solvent (e.g., acetone) before visual or spectroscopic observations are made (Argauer and Cantelo 1972). The dyes do not effectively mark all insects, and not all insects can tolerate the dyes, so preliminary evaluations are needed to verify the efficacy of each marker dye for use with each insect species. For example, Gast and Landin (1966) evaluated the efficacy of 60 dyes incorporated in larval boll weevil diets at 100 and 1,000 ppm and found that only Calco Oil Red N1700 effectively imparted a long-lasting color to the insects.

European corn borer, Ostrinia nubilalis (Hübner), and southwestern corn borer, Diatraea grandiosella Dyar (Chippendale 1979, Calvin and Van Duyn 1999, Knutson and Davis 1999), are important pests of corn in the United States. Both insects are controlled effectively with the newly available transgenic Bacillus thuringiensis (Bt)-corn hybrids, but there is concern that these pests could develop resistance. So, the EPA (1998) has mandated the implementation of a "highdose refuge resistance management strategy." In an effective resistance management strategy, susceptible corn borer adults must be able to disperse from refuge plantings into Bt-corn fields to mate with potentially resistant adults (Ostlie et al. 1997). Such matings would produce offspring that are incapable of surviving on Bt-corn as long as resistance is a recessive trait. Our understanding of corn borer moth dispersal is based on dispersal observations on the European corn borer in the central plains of North America (Showers et al. 2001), where conditions are relatively humid. In this region, the corn borers spend a lot of time outside the corn fields. On the semiarid western high plains of North America, the European and southwestern corn borers seem to spend more time in the irrigated corn fields than in surrounding vegetation (Hunt et al. 2001). Improved understanding of corn borer dispersal behavior is needed to ensure that this resistance management strategy will be effective in both regions.

Two oil-soluble dyes have been used to internally mark the European corn borer: Sudan Red 7B (C.I. 26050) and Sudan Blue 670 (C.I. 61554) (Ostlie et al. 1984, Hunt et al. 2000). These two dyes and the following six additional candidates were tested in preliminary trials for use as markers for the southwestern corn borer: Neutral Red (C.I. 50040), Janis Green B (C.I. 11050), Nile Blue A (C.I. 51180), Crocein Scarlet 7B (C.I. 27165), Sudan Black B (C.I. 26150), and Acridine Orange (C.I. 46005) (Sigma-Aldrich, St. Louis,
MO). Only Sudan Red 7B and Sudan Blue 670 were retained well enough to produce marked larvae (L. L. B., unpublished data). These two dyes were also tested at three rates $(100,200$, and $400 \mathrm{ppm})$, and the 100-ppm rate of Sudan Red 7B and the 200-ppm rate of Sudan Blue 670 were found to produce well-marked larvae without obvious developmental problems (L. L. B., unpublished data). The following study was conducted to make more detailed evaluations of potential biological and developmental effects of these dyes on the southwestern corn borer. The objectives of our studies were to determine (1) if Sudan Red 7B and Sudan Blue 670 exert any effects on the biology of southwestern corn borer at the tested rate and (2) if Sudan Red 7B and Sudan Blue 670 were effective in marking adults of the southwestern corn borer.

\section{Materials and Methods}

Stock Colony and Rearing Conditions. Southwestern corn borers used in this study were obtained from a colony maintained at Kansas State University, Southwest Research and Extension Center (SWREC), Garden City, KS. The colony was started the previous fall from larvae collected in the field and maintained on a standard wheat germ-based meridic diet (Davis 1976) supplied by Bio-Serve (Frenchtown, NJ) with $0.5 \mathrm{mg}$ neomycin sulfate/liter included as an antibiotic. Experimental insects were reared on three different diets: a control or "standard" diet, red diet, and blue diet. One gram of dye (Sudan Red 7B C.I. 26050 or Sudan Blue 670 C.I. 61554; Sigma Aldrich) was added to $10 \mathrm{ml}$ of corn oil to form the stock dye solution (Cantelo 1973, Ostlie et al. 1984). Two milliliters of the stock solution was added to 1 liter of prepared diet (200 ppm) and mixed in a blender.

The experiment followed a randomized complete block design (RCBD) with four replications (blocks). Replicates were started on successive days so readings could also be staggered. There were 30 neonates for each replicate. Individual neonates were reared in $2-\mathrm{oz}(59 \mathrm{ml})$ plastic rearing cups with a diet cube of known weight. Larvae were held on a table under a $500-\mathrm{W}$ incandescent light bulb with a photoperiod of 16:8 (L:D) $\mathrm{h}$ and ambient temperature of $27 \pm 2^{\circ} \mathrm{C}$. Blocks were rotated daily on the table to equalize light exposure, and all data were recorded for individual insects.

Larvae. Every 5 d, survival, larval weight, and diet cube weight were recorded, and fecal matter and excess moisture were removed with tissue paper. Diet consumption $(\mathrm{mg})$ was estimated as the reduction in diet weight within each interval. Laval development time was calculated as the number of days from inoculation to pupation.

Pupae. Survival to pupation was calculated as the number of larvae that pupated divided by the number of neonates used for inoculation. Pupal survival was calculated as number of adults emerged divided by the number of pupae. Pupae were weighed 24 and $48 \mathrm{~h}$ after pupation and inspected visually for marker presence. Pupation time was calculated as the number of 
days from pupal formation to adult emergence. $\mathrm{Cu}-$ mulative pupation was calculated as percentage of the male and female pupae that accumulated over time relative to the total number of pupae that emerged from each diet.

Adults. Adults were inspected visually for the marker by squeezing the insects to extend the abdomen so the dye could be seen through the intersegmental membranes of the abdomen. Total survival to adulthood was calculated as the number of adults emerged relative to the number of neonates inoculated. Any deformed adults were tallied. Cumulative adult emergence was calculated as percentage of males and females that accumulated over time relative to total emergence. Total development time was calculated as number of days from inoculation to adult emergence. Adults of $D$. grandiosella do not feed (Chippendale 1979), so they were left in their respective rearing cups until they died. Adult longevity was calculated as the number of days from emergence until death. Eggs deposited by the unmated females in rearing cups were counted and inspected visually for marker presence. Adults were inspected visually to detect the marker before drying them in an oven at $60^{\circ} \mathrm{C}$ for $2 \mathrm{~d}$ and weighing them.

Mating and F1 Generation. Another group of southwestern corn borers were reared on the same diets and rearing conditions as described above to generate a large number of pupae. Pupae from each diet were sexed, and male (14-24 first replicate, 30-47 second replicate) and female (13-24 first replicate, 18-38 second replicate) pupae for each mating combination were placed in open dishes in an oviposition cage (3 $\mathrm{mm}$ mesh hail screen cylinder, $20 \mathrm{~cm}$ diameter by 30 $\mathrm{cm}$ high, wrapped with wax paper) for emergence, mating, and oviposition. Wet cotton balls were added daily to maintain humidity. Males and females from each treatment were paired with the opposite sex from each of the other treatments to produce seven pairings. Adults were held for $9 \mathrm{~d}$. Females were dissected to determine mating status as evidenced by the presence of a spermatophore in the bursa copulatrix. The eggs on the wax paper were cut out and placed in rearing cups, and the number of enclosing neonates was recorded. Thirty neonates from each mating combination were reared on control diet (five neonates per 2-oz [59 ml] cup) to record survival and establishment on the diet. These readings were made after $5 \mathrm{~d}$, when the larvae were in the second instar. The experiment was repeated to give two replicates.

Statistical Analysis. Effects of dyes on southwestern corn borer survival were analyzed as binomial responses under RCBD with a one-way (three levels) treatment structure using GLIMMIX MACRO model and PROC MIXED (Littell et al. 1996) in SAS (SAS Institute 1999-2000). Data were first transformed using the logit link function. Survival in each indicator (time interval) was dependent on the survival in the previous indicator, unless it was calculated against the initial inoculation. Larval diet consumption $(\mathrm{mg})$, pupal weight $(\mathrm{mg})$, development time (d), adult longevity (d), and adult dry weight (mg) were analyzed by two-factor analysis of variance (ANOVA; diet and sex) using PROC MIXED in SAS (Littell et al. 1996). Treatment means were separated by the least significant difference (LSD) procedure (Littell et al. 1996). Data for development time to $50 \%$ pupation and adult emergence were analyzed with probit analysis for correlated data using the log probit transformation (Throne et al. 1995). Data were checked for homogeneity of slopes and intercepts, and development times were compared across diet treatments (Robertson and Preisler 1992). A $t$-test was used to determine whether the ratio of females in the population differed from 0.5 . Female fecundity was analyzed by one-way ANOVA using PROC MIXED in SAS, and means were separated by LSD. Repetitions of the cross-mating experiment were treated as blocks. Number of males available per female to mate, proportion of females mated, neonates per mated female, and F1 larval survival to second instar were analyzed by one-way ANOVA using PROC MIXED in SAS. Treatment means were separated by LSD with the Tukey multiple comparisons approximation to $P$ values (Littell et al. 1996).

\section{Results}

Eggs, larvae, pupae, and adults of southwestern corn borers reared on Sudan Red 7B- and Sudan Blue 670 -incorporated diets were all readily identifiable. Adults could be squeezed gently to reveal the dye color in the exposed intersegmental membranes of the abdomen.

Larvae. Larval survival for neonate to $20 \mathrm{~d}$ old averaged $93-100 \%$ over the different time intervals for the three treatments (data not shown). Larval survival from $21 \mathrm{~d}$ old to pupae averaged 75-83\% (Table 1), and there were no significant differences across treatments. The GLIMMIX MACRO model used to test larval survival data indicates a good fit to the data for $21 \mathrm{~d}$ old to pupation, because deviance values were close to $\chi^{2}$ critical values, and extra dispersion scale values were between 0.9 and 1.0 (Table 1 ).

The main effects of diet and sex on consumption were significant for several of the early time intervals and in the overall neonate-pupation interval (Table 2 ). In the interval from neonate to pupa, larvae on the red diet consumed more than larvae on the control or blue diets $(t=-2.92,-4.14 ; \mathrm{df}=232,232 ; P=0.004$, 0.001 , respectively). Female larvae consumed more diet than did males $(t=8.53 ; \mathrm{df}=232, P=0.001)$, independent of diet treatment. There was also an interaction $(P<0.05)$ between diet and sex for consumption in two of the five time intervals (Table 2 ; Fig. 1, A and B). During the 11- to 15-d interval, male consumption was higher on the red diet $(n=42$, $473.14 \pm 19.97 \mathrm{mg} /$ larva $)$ than on the control $(n=48$, $374.73 \pm 18.68 \mathrm{mg} /$ larva $)$ and blue $(n=36,396.86 \pm$ $21.86 \mathrm{mg} /$ larva $)$ diets $(t=-3.60,-2.60 ; \mathrm{df}=232,232$; $P=0.001,0.010$, respectively). However, female consumption was higher on the red $(n=44,436.36 \pm 19.51$ $\mathrm{mg} /$ larva $)$ and control $(n=32,447.38 \pm 22.87 \mathrm{mg} /$ larva) diets than on the blue diet $(n=39,363.33 \pm$ 
Table 1. Survival (mean \pm SE) of southwestern corn borer reared on dye-incorporated and control meridic diets, Glimmix model statistics, and ANOVA results

\begin{tabular}{|c|c|c|c|c|c|}
\hline & \multicolumn{5}{|c|}{ Survival $^{a}$} \\
\hline & $\begin{array}{l}\text { 21-d-old larvae } \\
\text { to pupae }\end{array}$ & $\begin{array}{l}\text { Neonates to } \\
\text { pupation }\end{array}$ & $\begin{array}{l}\text { Adult emergence } \\
\text { from pupae }\end{array}$ & $\begin{array}{l}\text { Neonates to } \\
\text { adult emergence }\end{array}$ & Normal adults \\
\hline Control diet & $1.44 \pm 0.41(0.81)$ & $1.35 \pm 0.37(0.79)$ & $1.83 \pm 0.55(0.86) \mathrm{a}$ & $0.78 \pm 0.39(0.68)$ & $1.58 \pm 0.31(0.83)$ \\
\hline Sudan Red 7B diet & $1.57 \pm 0.42(0.83)$ & $1.06 \pm 0.36(0.74)$ & $3.90 \pm 0.82(0.98) b$ & $0.99 \pm 0.39(0.73)$ & $2.11 \pm 0.35(0.90)$ \\
\hline Sudan Blue 670 diet & $1.08 \pm 0.40(0.75)$ & $0.78 \pm 0.36(0.68)$ & $2.67 \pm 0.62(0.93) \mathrm{ab}$ & $0.54 \pm 0.38(0.63)$ & $1.02 \pm 0.28(0.73)$ \\
\hline \multicolumn{6}{|l|}{ Glimmix } \\
\hline Deviance & 330.02 & 395.90 & 128.36 & 425.80 & 205.12 \\
\hline$\chi^{2}$ critical value $(n=3)$ & 376.60 & 402.10 & 298.60 & 402.10 & 259.90 \\
\hline Extra dispersion scale & 0.980 & 0.987 & 0.851 & 0.995 & 1.013 \\
\hline \multicolumn{6}{|l|}{ ANOVA } \\
\hline Den df $(2 \text { num df })^{b}$ & 330 & 354 & 257 & 354 & 221 \\
\hline$F$ & 1.22 & 1.88 & 4.83 & 1.22 & 2.98 \\
\hline$P$ & 0.295 & 0.155 & 0.009 & 0.296 & 0.053 \\
\hline
\end{tabular}

${ }^{a}$ Transformed means using logit link, numbers in parentheses are the backtransformed proportions that survived. Means in columns followed by the same or no letter are not significantly different $(P>0.05$, GLIMMIX MACRO, PROC MIXED).

${ }^{b}$ Den, denominator; num, numerator.

$20.72 \mathrm{mg} /$ larva; $t=-2.57,-2.72 ; \mathrm{df}=232,232 ; P=$ $0.011,0.007$, respectively). During the $21 \mathrm{~d}$ old-pupation interval, male consumption did not differ across treatments $(P>0.05)$. However, female consumption was higher on the red diet $(n=44,2702.21 \pm 156.49$ $\mathrm{mg} /$ larva) than on the control $(n=32,2104.34 \pm$ $176.46 \mathrm{mg} /$ larva $)$ and blue $(n=39,2164.34 \pm 163.39$ $\mathrm{mg}$ /larva $)$ diets $(t=-2.98,-2.84 ; \mathrm{df}=232,232 ; P=$ $0.003,0.005$, respectively).

The main effects of diet and sex on larval weight were significant for several of the time intervals (Table $3)$. There was also an interaction $(P<0.05)$ between diet and sex for larval weight on days 10 and 20 (Table 3; Fig. 1, C and D). On day 10, male larvae on the control diet $(n=48,8.67 \pm 0.92 \mathrm{mg} /$ larva) weighed less than males on the red $(n=42,12.26 \pm 0.94$ $\mathrm{mg} /$ larva $)$ and blue $(n=36,12.30 \pm 0.98 \mathrm{mg} /$ larva $)$ diets $(t=-4.08,3.94 ; \mathrm{df}=232,232 ; P=0.001,0.001$, respectively), but female larval weight did not differ $(P>0.05)$. On day 20, male larval weight did not differ across diets $(P>0.05)$, but female larvae on the red $\operatorname{diet}(n=44,81.42 \pm 8.28 \mathrm{mg} /$ larva $)$ weighed less $(t=$ 2.66; $\mathrm{df}=232 ; P=0.008)$ than females on the control $\operatorname{diet}(n=32,103.30 \pm 8.94 \mathrm{mg} /$ larva $)$.

Females took longer to develop than males across diets $(t=4.86 ; \mathrm{df}=232 ; P=0.001 ;$ Table 4$)$. However, there was an interaction $(P<0.05)$ between diet and sex in mean larval development time, because development times for male larvae did not differ across diets $(P>0.05)$, whereas development times for the females were longer on the red diet $(n=44)$ than on the control diet $(n=32 ; t=-2.30 ; \mathrm{df}=232 ; P=0.022$; Fig. 2A).

Pupae. Adult emergence for pupae reared on the red diet was significantly higher than for pupae reared on the control diet $(t=-2.90 ; \mathrm{df}=257 ; P=0.004)$, but not for pupae reared on the blue diet $(P>0.05$; Table 1). The GLIMMIX MACRO model indicated a poor fit for this data set because the deviance value was much lower than the $\chi^{2}$ value, and the extra dispersion scale value was $<0.9$ (Table 1 ). The weights of pupae were similar within sexes (Table 3), but

Table 2. Diet consumption (mean \pm SE) of southwestern corn borer larvae at different time intervals reared on dye-incorporated and control meridic diets and ANOVA results

\begin{tabular}{|c|c|c|c|c|c|c|c|c|}
\hline \multirow{2}{*}{ Diet } & \multirow{2}{*}{ Sex } & \multirow{2}{*}{$n$} & \multicolumn{6}{|c|}{ Diet consumed $(\mathrm{mg}) /$ larva/time interval } \\
\hline & & & Neonate-5 d & $6-10 \mathrm{~d}$ & $11-15 \mathrm{~d}$ & $16-20 \mathrm{~d}$ & $21 \mathrm{~d}$-pupation & Neonate-pupation \\
\hline Control & - & 80 & $367.69 \pm 10.21 \mathrm{a}$ & $257.38 \pm 5.50 \mathrm{a}$ & $411.05 \pm 14.76 \mathrm{a}$ & $822.31 \pm 46.72$ & $1879.17 \pm 132.02$ & $3715.42 \pm 97.08 \mathrm{a}$ \\
\hline Sudan Red 7B & - & 86 & $391.09 \pm 9.93 \mathrm{~b}$ & $315.56 \pm 5.20 \mathrm{~b}$ & $454.75 \pm 13.96 \mathrm{~b}$ & $784.70 \pm 44.36$ & $2094.34 \pm 127.59$ & $4034.75 \pm 93.20 \mathrm{~b}$ \\
\hline Sudan Blue 670 & - & 75 & $359.59 \pm 10.23 \mathrm{a}$ & $335.37 \pm 5.60 \mathrm{c}$ & $380.10 \pm 14.95 \mathrm{a}$ & $719.24 \pm 47.15$ & $1787.55 \pm 132.50$ & $3579.03 \pm 97.57 \mathrm{a}$ \\
\hline All diets & Male & 126 & $363.98 \pm 9.27 \mathrm{a}$ & $300.45 \pm 4.32$ & $414.91 \pm 11.61$ & $794.42 \pm 37.92$ & $1517.08 \pm 116.79 \mathrm{a}$ & $3389.81 \pm 83.42 \mathrm{a}$ \\
\hline All diets & Female & 115 & $381.61 \pm 9.44 \mathrm{~b}$ & $305.09 \pm 4.53$ & $415.69 \pm 12.17$ & $756.41 \pm 39.51$ & $2323.63 \pm 119.55 b$ & $4162.99 \pm 85.90 \mathrm{~b}$ \\
\hline \multicolumn{9}{|l|}{$\operatorname{Diet}(\mathrm{df}=2,232)$} \\
\hline$F$ & & & 6.13 & 54.1 & 6.78 & 1.39 & 2.72 & 9.19 \\
\hline$P$ & & & $0.002^{a}$ & $<0.001^{a}$ & $0.001^{a}$ & 0.251 & 0.068 & $0.001^{a}$ \\
\hline \multicolumn{9}{|l|}{$\operatorname{Sex}(\mathrm{df}=1,232)$} \\
\hline$F$ & & & 5.14 & 0.55 & 0.00 & 0.58 & 51.75 & 72.80 \\
\hline$P$ & & & $0.024^{a}$ & 0.460 & 0.963 & 0.448 & $<0.001^{a}$ & $<0.001^{a}$ \\
\hline \multicolumn{9}{|l|}{$\begin{array}{l}\text { Diet } \times \text { Sex } \\
\quad(\mathrm{df}=2,232)\end{array}$} \\
\hline$F$ & & & 1.76 & 1.92 & 4.52 & 2.95 & 4.08 & 2.04 \\
\hline$P$ & & & 0.174 & 0.148 & $0.012^{a}$ & 0.054 & $0.018^{a}$ & 0.133 \\
\hline
\end{tabular}

Means in columns followed by the same or no letter are not significantly different for diet or sex $(P>0.05$, PROC MIXED, LS MEANS). ${ }^{a}$ Significant $(P<0.05)$ 

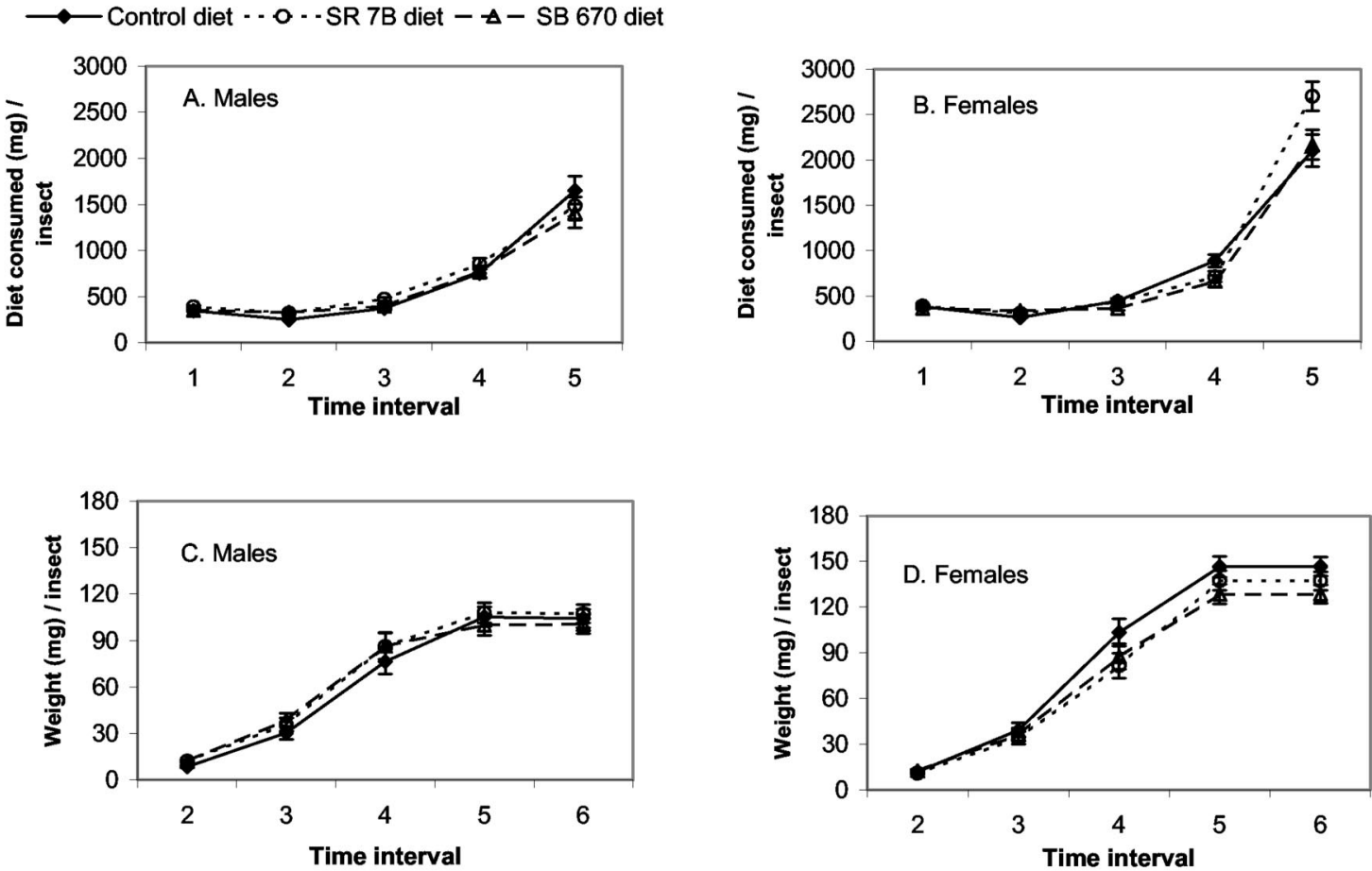

Fig. 1. Diet consumption and weight (mean $\pm \mathrm{SE}$ ) at different time intervals from neonate to pupation of southwestern corn borer reared on dye-incorporated and control meridic diets (time interval $1=$ neonate to 5 -d-old larvae, $2=6$ - to 10 -d-old larvae, 3 = 11- to 15 -d-old larvae, $4=16$ - to 20 -d-old larvae, $5=21$-d-old larvae to pupae (diet consumption), $5=24$-h pupae (weight), and $6=48$-h pupae (weight).

female pupae weighed more than male pupae across diets at 24 and $48 \mathrm{~h}(t=11.91 ; \mathrm{df}=232 ; P=0.001$; Table 3; Fig. 1, C and D).

The main effects of diet on pupal development time were significant. Pupae reared on the red diet developed faster than did pupae reared on the blue diet $(t=$ 3.24; $\mathrm{df}=232 ; P=0.001)$, independent of sex (Table 4). Male pupation started $21 \mathrm{~d}$ after inoculation on the control and blue diets and $22 \mathrm{~d}$ after inoculation on the red diet (Fig. 3). Females began to pupate $21 \mathrm{~d}$ after inoculation on the blue diet and after 23 and $25 \mathrm{~d}$ on the control and red diets, respectively. Mean time to $50 \%$ pupation did not differ across diets for males, but mean time to $50 \%$ pupation was longer for females on the red diet than on the control diet (Table 5). Both slope and intercept were significant for two of the

Table 3. Larval and pupal weight (mean \pm SE) of southwestern corn borer at different time intervals reared on dye-incorporated and control meridic diets and ANOVA results

\begin{tabular}{|c|c|c|c|c|c|c|c|}
\hline \multirow{2}{*}{ Diet } & \multirow{2}{*}{ Sex } & \multirow{2}{*}{$n$} & \multicolumn{5}{|c|}{ Larval and pupal weight $(\mathrm{mg}) /$ time interval } \\
\hline & & & $6-10$ d larvae & $11-15$ d larvae & $16-20 \mathrm{~d}$ larvae & 24-h pupae & 48-h pupae \\
\hline Control & - & 80 & $10.33 \pm 0.84 \mathrm{a}$ & $34.83 \pm 3.90$ & $89.90 \pm 7.53$ & $125.85 \pm 6.02 \mathrm{~b}$ & $125.39 \pm 5.53 \mathrm{~b}$ \\
\hline Sudan Red 7B & - & 86 & $11.59 \pm 0.82 b$ & $34.88 \pm 3.83$ & $83.88 \pm 7.40$ & $122.57 \pm 5.60 \mathrm{~b}$ & $122.30 \pm 5.46 \mathrm{~b}$ \\
\hline Sudan Blue 670 & - & 75 & $12.39 \pm 0.84 b$ & $37.55 \pm 3.90$ & $86.95 \pm 7.55$ & $114.18 \pm 6.03 \mathrm{a}$ & $114.44 \pm 5.53 \mathrm{a}$ \\
\hline All diets & Male & 126 & $11.08 \pm 0.78$ & $34.98 \pm 3.70$ & $83.90 \pm 7.10$ & $104.39 \pm 5.81 \mathrm{a}$ & $104.03 \pm 5.31 \mathrm{a}$ \\
\hline All diets & Female & 115 & $11.80 \pm 0.80$ & $36.52 \pm 3.73$ & $90.71 \pm 7.20$ & $137.35 \pm 5.85 \mathrm{~b}$ & $137.39 \pm 5.35 \mathrm{~b}$ \\
\hline \multicolumn{8}{|l|}{$\operatorname{Diet}(\mathrm{df}=2,232)$} \\
\hline$F$ & & & 4.73 & 0.65 & 0.58 & 5.65 & 5.23 \\
\hline$P$ & & & $0.0106^{a}$ & 0.522 & 0.560 & $0.004^{a}$ & $0.006^{a}$ \\
\hline \multicolumn{8}{|l|}{$\operatorname{Sex}(\mathrm{df}=1,232)$} \\
\hline$F$ & & & 1.76 & 0.49 & 2.72 & 131.33 & 141.80 \\
\hline$P$ & & & 0.186 & 0.484 & 0.100 & $<0.001^{a}$ & $<0.001^{a}$ \\
\hline \multicolumn{8}{|l|}{$\begin{array}{l}\text { Diet } \times \text { Sex } \\
\quad(\mathrm{df}=2,232)\end{array}$} \\
\hline$F$ & & & 6.47 & 2.74 & 4.47 & 1.97 & 2.55 \\
\hline$P$ & & & $0.002^{a}$ & 0.067 & $0.012^{a}$ & 0.142 & 0.081 \\
\hline
\end{tabular}

Means in columns followed by the same or no letter are not significantly different for diet or sex $(P>0.05$, PROC MIXED, LS MEANS). ${ }^{a}$ Significant $(P<0.05)$. 
Table 4. Development time, adult longevity, and adult dry weight (mean \pm SE) of southwestern corn borer reared on dye-incorporated and control meridic diets and ANOVA results

\begin{tabular}{|c|c|c|c|c|c|c|c|c|}
\hline \multirow{2}{*}{ Diet } & \multirow{2}{*}{ Sex } & \multirow{2}{*}{$n$} & \multicolumn{3}{|c|}{ Development time (days) } & \multirow{2}{*}{$n$} & \multirow{2}{*}{$\begin{array}{c}\text { Adult } \\
\text { longevity (days) }\end{array}$} & \multirow{2}{*}{$\begin{array}{c}\text { Adult } \\
\text { dry weight }(\mathrm{mg})\end{array}$} \\
\hline & & & Larvae & Pupae & Neonate-adult & & & \\
\hline Control & - & 80 & $31.90 \pm 1.03$ & $9.65 \pm 0.20 \mathrm{ab}$ & $41.52 \pm 1.05$ & 63 & $7.14 \pm 0.30$ & $12.40 \pm 0.45 b$ \\
\hline Sudan Red 7B & - & 86 & $32.40 \pm 0.99$ & $9.33 \pm 0.20 \mathrm{a}$ & $41.70 \pm 1.01$ & 74 & $7.50 \pm 0.30$ & $11.28 \pm 0.43 \mathrm{a}$ \\
\hline Sudan Blue 670 & - & 75 & $32.34 \pm 1.03$ & $10.10 \pm 0.17 \mathrm{~b}$ & $42.42 \pm 1.05$ & 50 & $7.06 \pm 0.34$ & $10.40 \pm 0.50 \mathrm{a}$ \\
\hline All diets & Male & 126 & $30.07 \pm 0.91 \mathrm{a}$ & $9.67 \pm 0.13$ & $39.73 \pm 0.91 \mathrm{a}$ & 88 & $7.24 \pm 0.27$ & $10.40 \pm 0.41 \mathrm{a}$ \\
\hline All diets & Female & 115 & $34.35 \pm 0.93 b$ & $9.71 \pm 0.14$ & $44.03 \pm 0.94 \mathrm{~b}$ & 98 & $7.23 \pm 0.25$ & $12.33 \pm 0.40 \mathrm{~b}$ \\
\hline $\operatorname{Diet}(\mathrm{df}=2,232)$ & & & & & & $(\mathrm{df}=2,178)$ & & \\
\hline F & & & 0.13 & 5.27 & 0.34 & & 0.76 & 6.96 \\
\hline$P$ & & & 0.882 & $0.006^{a}$ & 0.709 & & 0.468 & $0.001^{a}$ \\
\hline $\operatorname{Sex}(\mathrm{df}=1,232)$ & & & & & & $(\mathrm{df}=1,178)$ & & \\
\hline F & & & 23.61 & 0.04 & 21.71 & & 0.00 & 21.33 \\
\hline$P$ & & & $<0.001^{a}$ & 0.835 & $<0.001^{a}$ & & 0.983 & $<0.001^{a}$ \\
\hline Diet $\times \operatorname{Sex}(\mathrm{df}=2,232)$ & & & & & & $(\mathrm{df}=2,178)$ & & \\
\hline F & & & 4.51 & 1.84 & 5.23 & & 3.37 & 2.38 \\
\hline$P$ & & & $0.012^{a}$ & 0.161 & $0.005^{a}$ & & $0.036^{a}$ & 0.095 \\
\hline
\end{tabular}

${ }^{a}$ Significant $(P<0.05)$.

Means in columns followed by the same or no letter are not significantly different for diet or sex $(P>0.05$, PROC MIXED, LS MEANS).
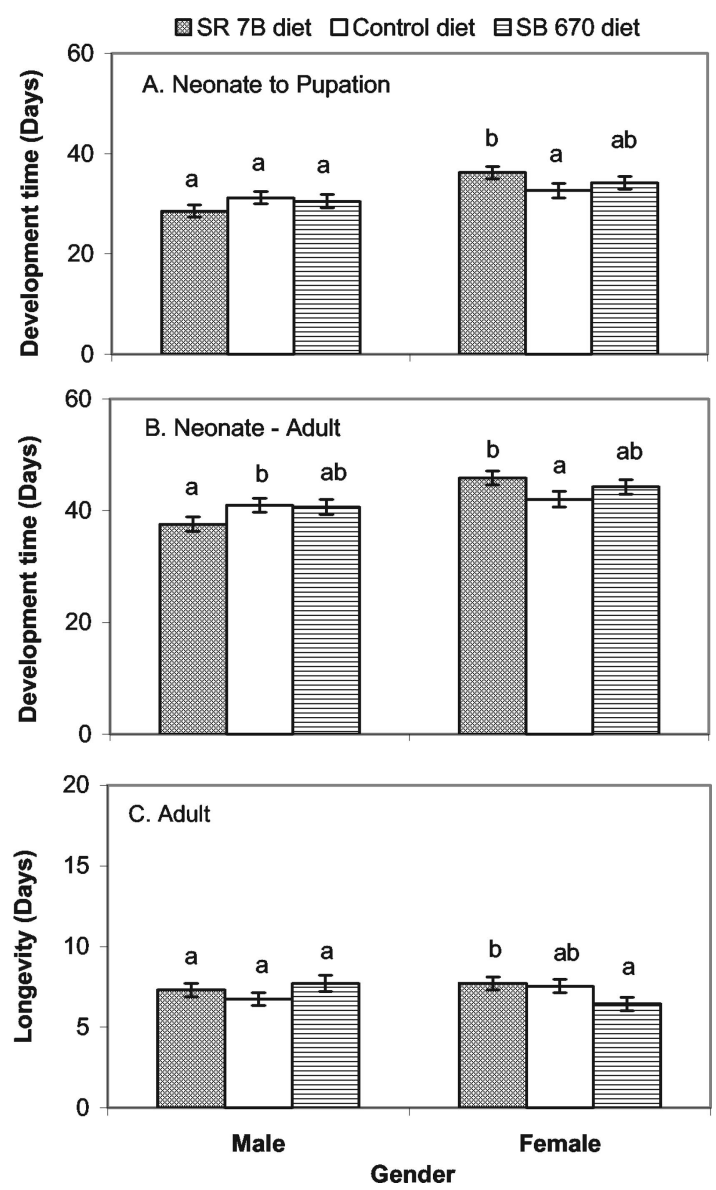

Fig. 2. Development time and adult longevity (mean \pm $\mathrm{SE}$ ) of southwestern corn borer reared on dye-incorporated and control meridic diets. Means with the same letter are not significantly different within sexes $(P>0.05$, PROC MIXED, LSMEANS). three comparisons across diets for males but not for females.

Adults. Total emergence of adults averaged 63-73\% of starting neonates and did not differ across diet treatments (Table 1). The percentage of adults that were "normal" (no wing deformities) averaged 83 and $90 \%$ for the control and red diets, respectively, but only $73 \%$ for the blue diet (Table 1 ). Although the blue diet seemed to have $20 \%$ more deformed moths than the control diet, this difference was not statistically significant (Table 1). Total time of development was
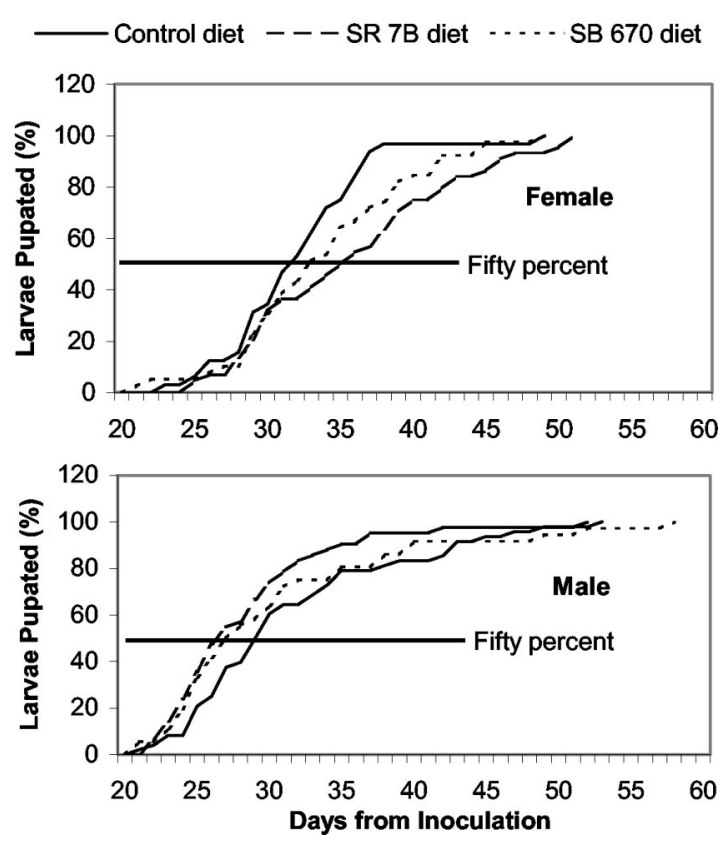

Fig. 3. Cumulative pupation of male and female southwestern corn borer larvae reared on dye-incorporated and control meridic diets. 
Table 5. Comparison of times to $50 \%$ pupation and adult eclosion of southwestern corn borer reared on dye-incorporated and control meridic diets at $27 \pm 2^{\circ} \mathrm{C}$

\begin{tabular}{|c|c|c|c|c|c|}
\hline & \multirow{2}{*}{ Comparison $^{a}$} & \multirow{2}{*}{ Development time (days) } & \multirow{2}{*}{ Ratio $(\mathrm{CL})^{b}$} & \multicolumn{2}{|c|}{ Significance of ${ }^{c}$} \\
\hline & & & & Slope & Intercept \\
\hline \multicolumn{6}{|l|}{ Pupation } \\
\hline \multirow[t]{3}{*}{ Males } & Red versus control & 27.2 versus 30.1 & $0.90(0.81-1.01) \mathrm{NS}$ & + & + \\
\hline & Blue versus control & 28.6 versus 30.1 & $0.95(0.82-1.09) \mathrm{NS}$ & - & - \\
\hline & Blue versus red & 28.6 versus 27.2 & $1.05(0.93-1.19) \mathrm{NS}$ & + & + \\
\hline \multirow[t]{3}{*}{ Females } & Red versus control & 34.8 versus 31.2 & $1.12(1.01-1.23)^{*}$ & - & - \\
\hline & Blue versus control & 32.8 versus 31.2 & $1.05(0.95-1.16) \mathrm{NS}$ & - & - \\
\hline & Red versus blue & 34.8 versus 32.8 & $1.06(0.95-1.18) \mathrm{NS}$ & - & - \\
\hline \multicolumn{6}{|c|}{ Adult eclosion } \\
\hline \multirow[t]{3}{*}{ Males } & Red versus control & 36.4 versus 40.2 & $0.90(0.82-0.99)^{*}$ & + & + \\
\hline & Blue versus control & 37.9 versus 40.2 & $0.94(0.83-1.07) \mathrm{NS}$ & - & - \\
\hline & Blue versus red & 37.9 versus 36.4 & $1.04(0.94-1.16) \mathrm{NS}$ & + & + \\
\hline \multirow[t]{3}{*}{ Females } & Red versus control & 43.8 versus 40.6 & $1.08(0.99-1.18) \mathrm{NS}$ & + & + \\
\hline & Blue versus control & 43.0 versus 40.6 & $1.06(0.98-1.15) \mathrm{NS}$ & - & + \\
\hline & Red versus blue & 43.8 versus 43.0 & $1.02(0.92-1.12) \mathrm{NS}$ & - & - \\
\hline
\end{tabular}

NS, not significant $(P=0.05)$; *, significant $(P<0.05)$.

${ }^{a}$ For each comparison, numerator of the ratio is listed first.

${ }^{b}$ The two treatment development times differ when the confidence limits on their ratio does not include 1 .

${ }^{c}+$ Slope or intercept are significantly different at 0.05 level using probit analysis of correlated data (Throne et al. 1995)

longer for females than for males $(t=4.66$; $\mathrm{df}=232$; $P=0.001$ ), independent of diet (Table 4). However, there was an interaction $(P<0.05)$ between diet and sex for total development time, because males on the red diet $(n=42)$ developed faster $(t=2.26$; $\mathrm{df}=232$; $P=0.025)$ than males on the control diet $(n=48)$, whereas females on the red diet $(n=44)$ developed slower $(t=-2.28$; df $=232 ; P=0.024)$ than females on the control diet ( $n=32 ;$ Fig. $2 \mathrm{~B}$ ). Male emergence began $31 \mathrm{~d}$ after inoculation on the red diet and $33 \mathrm{~d}$ after inoculation on the control and blue diets (Fig. 4).
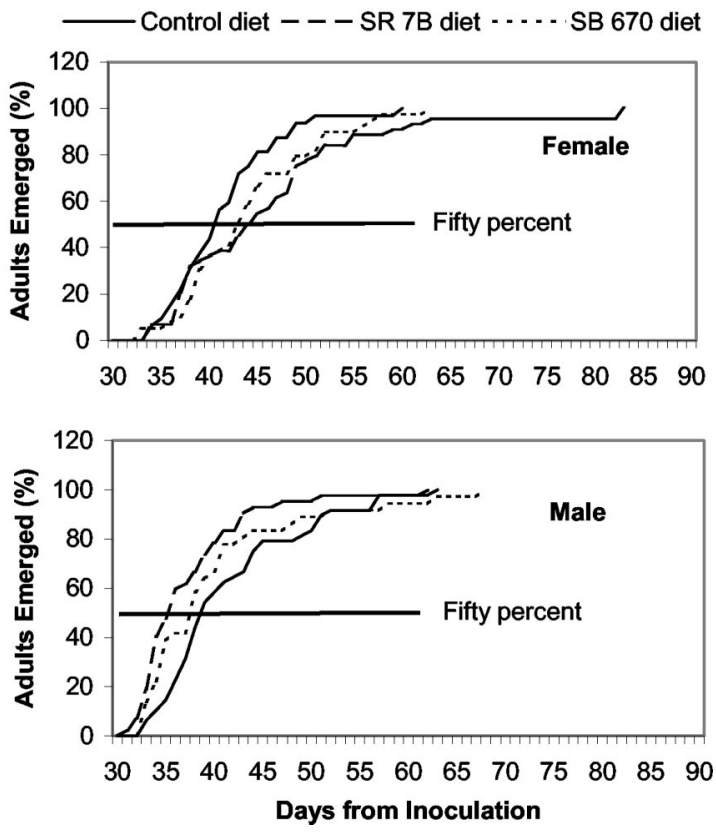

Fig. 4. Cumulative emergence of male and female southwestern corn borer adults reared on dye-incorporated and control meridic diets.
Female emergence began $33 \mathrm{~d}$ after inoculation on the blue diet and $34 \mathrm{~d}$ after inoculation on the control and red diets. Total time to $50 \%$ adult emergence did not differ across diets for females, but males developed faster on the red diet than they did on the control diet (Table 5). Slope and intercept were significant for two of the three comparisons across diets for males, and one slope and two intercepts were significant in the three comparisons across diets for females.

There was no effect of diet on sex ratio, nor did sex ratio differ from 0.5 in the control, red, or blue diets $(t=-1.52,0.64,0.55 ; \mathrm{df}=2,2,2 ; P=0.226,0.567,0.622$, respectively). The interaction between diet and sex on adult longevity was significant (Table 4), because male longevity was not different across diets, whereas female longevity was shorter for females on the blue diet $(n=30)$ than females on the red diet $(n=40 ; t=$ -2.46 ; df $=178 ; P=0.015$; Fig. $2 \mathrm{C}$ ). The main effects of diet and sex on adult dry weight were both significant (Table 4). Females were heavier than males $(t=$ 4.62; $\mathrm{df}=178 ; P=0.001)$ across diet treatments, and adults from the control diet were heavier than adults from the two dye treatments (Table 4). Unmated females left in the rearing cups laid 59-72 eggs per female and did not differ across diet treatments (Table $6)$.

Mating and F1 Generation. The number of males available per female was not significantly different $(P>0.05)$ across mating combinations (Table 6). The proportion of mated females, the number of neonate progeny per mated female, and the survival of neonates to second instar were not different $(P>0.05)$ across mating treatments (Table 6 ). There was a good correlation between the number of males per female and the proportion of females mated $(r=0.88, \mathrm{df}=$ $6, P=0.009)$. However, there was no correlation $(P>$ $0.05)$ between the proportion of females mated and the number of neonates per mated female. Dye marker was not transferred by mating, either from 
Table 6. Fecundity of virgin females, males available per female, mated females from cross matings, neonates per mated female, and F1 larval survival to second instar (mean \pm SE) of southwestern corn borer reared on dye- incorporated and control meridic diets and ANOVA results

\begin{tabular}{|c|c|c|c|c|c|c|}
\hline \multicolumn{2}{|c|}{ Matings } & \multirow{2}{*}{$\begin{array}{l}\text { Eggs/virgin } \\
\text { female }\end{array}$} & \multicolumn{4}{|c|}{ Results of cross matings } \\
\hline Male $(n)$ & Female $(n)$ & & $\begin{array}{l}\text { Males/ } \\
\text { female }\end{array}$ & $\begin{array}{l}\text { Proportion of } \\
\text { females mated }\end{array}$ & $\begin{array}{l}\text { Neonates/ } \\
\text { mated female }\end{array}$ & $\begin{array}{c}\text { Survival }(\%) \text { of } \mathrm{F} 1 \\
\text { (neonate-second instar) }\end{array}$ \\
\hline - & Control (29) & $72.34 \pm 12.14$ & - & - & - & - \\
\hline - & Red (41) & $60.10 \pm 10.95$ & - & - & - & - \\
\hline- & Blue $(30)$ & $59.23 \pm 11.93$ & - & - & - & - \\
\hline Red (21) & Control (17) & - & $1.23 \pm 0.35$ & $0.53 \pm 0.07$ & $22.67 \pm 11.75$ & $81.67 \pm 5.90$ \\
\hline Control (25) & Red (23) & - & $1.07 \pm 0.35$ & $0.51 \pm 0.07$ & $41.06 \pm 11.75$ & $83.33 \pm 5.90$ \\
\hline Red (31) & Red (21) & - & $1.72 \pm 0.35$ & $0.55 \pm 0.07$ & $32.41 \pm 11.75$ & $80.00 \pm 5.90$ \\
\hline Blue (25) & Control (21) & - & $1.23 \pm 0.35$ & $0.48 \pm 0.07$ & $26.60 \pm 11.75$ & $78.33 \pm 5.90$ \\
\hline Control (29) & Blue (31) & - & $0.94 \pm 0.35$ & $0.49 \pm 0.07$ & $27.44 \pm 11.75$ & $81.70 \pm 5.90$ \\
\hline Blue $(30)$ & Blue (34) & - & $0.90 \pm 0.35$ & $0.41 \pm 0.07$ & $36.54 \pm 11.75$ & $80.00 \pm 5.90$ \\
\hline Control (34) & Control (19) & - & $1.90 \pm 0.35$ & $0.65 \pm 0.07$ & $26.00 \pm 11.75$ & $83.33 \pm 5.90$ \\
\hline $\mathrm{df}$ & & 2,94 & 6,6 & 6,6 & 6,6 & 6,6 \\
\hline$F$ & & 0.64 & 1.48 & 2.66 & 0.42 & 0.65 \\
\hline$P$ & & 0.527 & 0.324 & 0.130 & 0.840 & 0.693 \\
\hline
\end{tabular}

$n$, number of males or females used in that mating combination.

Means within columns are not significantly different $(P>0.05$, PROC MIXED, LS MEANS).

males to females or vice versa. Marker was not transferred from marked males to their progeny; however, the progeny of marked females were marked and retained the color for 3-4 d when reared on control diet.

\section{Discussion}

Southwestern corn borers reared on Sudan Red 7B and Sudan Blue 670 diets were similar to those reared on the control diet except for a few minor effects. In general, females consumed more, weighed more, and took longer to develop than did males, as reported by other workers (Davis 1965, Ng et al. 1993). Food consumption and use by insects can vary with age, sex, and quality of food that collectively influence growth rate, development time, and final body weight (Waldbauer 1968, Slansky and Scriber 1985). Sex-specific responses were also observed in similar experiments with $D$. grandiosella using rubidium and cesium as markers (Qureshi 2003). In the current study, larvae consumed more of the red diet compared with the others, but that difference did not translate into a difference in weight. Rather, the pupae from the red and control diets were heavier than pupae from the blue diet. However, female adults from the control diet weighed more than did female adults from the red and blue diets. Female larvae on the red diet may have consumed more to compensate for energy involved in metabolizing the dye. However, female larvae on the blue diet could not compensate and had reduced pupal and adult weights compared with the other diets. Brewer (1982) found that larvae of Heliothis virescens (F.) reared on diet with another oil-soluble red dye, Calco Oil Red dye, were approximately twice as heavy as those reared on diets without the dye, although the same dye had no effect on the body weight of $A n$ thonomus grandis (Boheman) (Gast and Landin 1966).

Males and females exhibited different responses to the dyes in terms of development time. Female larval development was prolonged on the red diet compared with the control diet, and male pupation was pro- longed on the blue diet compared with the red diet. However, female development was slower on the red diet relative to the control diet, whereas male development was faster. Females are generally more resource-dependent and seemed to pay a higher price for dye metabolism than did males. However, the faster male development may not be advantageous to life history. Ostlie et al. (1984) reported that $0.6 \mathrm{~g}$ (600 $\mathrm{ppm}$ ) dye/liter diet reduced survival and delayed development of European corn borer reared on Sudan Blue 670-incorporated diet. Development times to $50 \%$ pupation and adult emergence were not different for the majority of comparisons across treatments. Hunt et al. (2000) and Ostlie et al. (1984) reported no effects of diet incorporated Sudan Red 7B on the European corn borer at rates of 400 and $600 \mathrm{ppm}$, respectively. Raun (1967) reported no effects of Calco Oil Red N-1700 dye on European corn borer compared with Orange GR and Calcozine Navy Blue MB dyes that reduced survival or retarded larval development. Females from the red diet lived longer than those from the blue diet. Some dyes are reported to prolong adult longevity. For example, Jones et al. (1975) found that females of Helicoverpa zea (Boddie) lived longer when reared on Calco Oil Red diet compared with ones reared on normal diet. However, Gast and Landin (1966) reported no detectable effects of the same dye on the longevity of adult $A$. grandis.

Feeding on the Sudan Red 7B and Sudan Blue 670 diets imparted red to pink or blue colors to larvae, pupae, and adults and to eggs deposited by marked females. All stages were readily marked and distinguishable from unmarked conspecifics, except that the densely scaled abdomens of some adults needed gentle squeezing with soft forceps to look for marker color through the intersegmental membranes. Because southwestern corn borers have a short adult life stage that does not feed, the likelihood of marker retention is greatly increased. However, other insect species were reported to lose marker color with time. Haagsma and Rust (1993) found that Reticulitermes 
hesperus (Isoptera) fed for $1 \mathrm{wk}$ on filter paper marked with three concentrations of Sudan Red 7B dye $(0.25$, 0.5 , and $0.75 \%$ ) had dramatically reduced retention of the dye after $6 \mathrm{~d}$, and no dye was evident after $24 \mathrm{~d}$. Furthermore, females tended to lose marker through their eggs. Gast and Landin (1966) and Daum et al. (1969) reported a similar loss of marker for A. grandis reared on Calco Oil Red N-1700 diet. In our studies, $>90 \%$ of dyed females oviposited and remained readily identifiable, as did their eggs. However, Burton and Snow (1970) reported that most eggs from H. zea females reared on Calco Red diet containing $1.0 \mathrm{~g}$ dye $/ \mathrm{kg}(1,000 \mathrm{ppm})$ diet were red, but not all were distinguishable from unmarked eggs.

Mated females laid viable eggs in all the cross-mating combinations from the three diets, indicating that diet had no effect on mating success. The correlation between the number of males per female and proportion of females mated indicates that increasing the number of males/female increases the chances of female mating success in the laboratory. Mating success was much lower in a similar study with $D$. grandiosella, where single males and females were paired (Qureshi 2003). Mating success may be reduced under laboratory conditions because males and females do not develop at the same rate and may not be in mating condition at the same time.

Larval progeny of marked adults had excellent survival to the second instar for all mating combinations, suggesting there was no effect of either dye on progeny fitness. However, marked larvae lost the color they acquired from their marked mothers after 3-4 d of feeding on the control diet. Wilkinson et al. (1972) reported similar observations for the imported cabbageworm, Pieris rapae L., reared on diet treated with Calco Oil Red N-1700.

Our results indicate that Sudan Red $7 \mathrm{~B}$ or Sudan Blue 670 can be incorporated in southwestern corn borer meridic diet at $200 \mathrm{ppm}$ to obtain marked adults for dispersal studies without major effects on their biology or behavior. The dyes will also be useful for short-term studies with marked larvae and oviposition behavior. The blue diet produced slightly longer pupal period, slightly lower adult dry weight, and slightly reduced female longevity compared with the control or red diet. Therefore, the red dye seems to be the best choice for studies requiring only one marker.

The focus of this study was to obtain marked adults, but marked eggs, larvae, and pupae were also obtained. Marked females could be released to study egg distribution, but larvae hatching from marked eggs could only be tracked for 3-4 $\mathrm{d}$ because they tend to lose color once removed from the marked diet. Marked pupae can be placed in the field to let adults emerge and disperse as they eclose, or caged marked adults can be taken to the field. The release of caged adults may expose them to a sudden change of environment that could trigger escape behavior rather than dispersal behavior. Marked adults could also be released to determine the relative efficiency of pheromone and black-light traps. We have recently concluded experiments that successfully employed both of these dyes to study dispersal of adult European and southwestern corn borers in the field (Qureshi 2003).

\section{Acknowledgments}

We thank R. Long for help in the diet preparation and cross-mating study; J. Pontius, KSU Statistics Department, for help with statistical analysis of the data; F. Davis, Mississippi State University, for providing important suggestions on improving the rearing of southwestern corn borers; J. Dyer, USDA-ARS Corn Insects and Crop Genetics Research Unit, for providing helpful information on rearing dye-marked European corn borer; and J. P. Michaud, KSU Entomology Department, for revision and useful comments. This article is Contribution 04-088-J from the Kansas Agricultural Experiment Station and represents work sponsored by F-205, NC205, Monsanto Co., and AgrEvo Co. Voucher specimens 149 are located in the Kansas State University Museum of Entomological and Prairie Arthropod Research.

\section{References Cited}

Argauer, R. J., and W. W. Cantelo. 1972. Spectrofluorometric determination of fluorecein-tagged tobacco hornworms. J. Econ. Entomol. 65: 539-542.

Brewer, F. D. 1982. Development and food utilization of tobacco budworm hybrids fed artificial diet containing oil soluble dyes. J. GA. Entomol. Soc. 17: 248-254.

Burton, R. L., and J. W. Snow. 1970. A marker for the corn earworm. J. Econ. Entomol. 63: 1976-1977.

Calvin, D. D., and J. W. Van Duyn. 1999. European corn borer, pp. 78-82. In K. L. Steffey, M. E. Rice, J. All, D. A. Andow, M. E. Gray, and J. W. Van Duyn (eds.), Handbook of corn insects. Entomological Society of America, Lanham, MD.

Cantelo, W. W. 1973. Dye markers for adults of tobacco hornworm. Environ. Entomol. 2: 393-396.

Chippendale, G. M. 1979. The southwestern corn borer, Diatraea grandiosella: case history of an invading insect. Univ. MO-Columbia Res. Bull. 1031: 52.

Coppedge, J. R., J. P. Spencer, H. E. Brown, C. J. Whitten, J. W. Snow, and J. E. Wright. 1979. A new dye marking technique for the screwworm. J. Econ. Entomol. 72: 40 42.

Daum, R. J., R. T. Gast, and T. B. Davich. 1969. Adult boll weevils marked with dyes in a cotton seed oil bait. J. Econ. Entomol. 62: 943-944.

Davis, F. M. 1965. Biology of the southwestern corn borer, Zeadiatraea grandiosella (Dyar), in Mississippi. PhD dissertation, Mississippi State University, Mississippi State, MS.

Davis, F. M. 1976. Production and handling of eggs of southwestern corn borer for host plant resistance studies. U.S. Dep. Agric.Tech. Bull. 74: 11.

[EPA] U.S. Environmental Protection Agency. 1998. Final report of the FIFRA Scientific Advisory Panel Subpanel on Bacillus thuringiensis (Bt) plant-pesticides and resistance management. http://www.epa.gov/scipoly/sap/ 1998/ february/ finalfeb.pdf.

Gast, R. T., and M. Landin. 1966. Adult boll weevils and eggs marked with dye fed in larval diet. J. Econ. Entomol. 59: 474- 475 .

Gould, F. 1988. Evolutionary biology and genetically engineered crops: consideration of evolutionary theory can aid in crop design. Bioscience 38: 26-33. 
Grace, J. K., and A. Abdallay. 1989. Evaluation of the dye marker Sudan Red 7B with Reticulitermes flavipes (Isoptera: Rhinotermitidae). Sociobiology 15: 71-77.

Graham, H. M., and C. L. Mangum. 1971. Larval diets containing dyes for tagging pink bollworm adults internally. J. Econ. Entomol. 64: 376-378.

Haagsma, K. A., and M. K. Rust. 1993. Two marking dyes useful for field populations of Reticulitermes hesperus (Isoptera: Rhinotermitidae). Sociobiology 23: 155-164.

Hagler, J. R., and C. G. Jackson. 2001. Methods for marking insects: current techniques and future prospects. Annu. Rev. Entomol. 46: 511-543.

Hendricks, D. E., M. P. Leal, S. H. Robinson, and N. S. Hernandez. 1971. Oil-soluble black dye in larval diet marks adults and eggs of tobacco budworm and pink bollworm. J. Econ. Entomol. 64: 1399-1401.

Hunt, T. E., R. L. Hellmich, J. M. Dyer, L. G. Higley, and J. F. Witkowski. 2000. Oil-soluble dyes for marking European corn borer (Lepidoptera:Crambidae). J. Entomol. Sci. 35: 338-341.

Hunt, T. E., L. G. Higley, J. F. Witkowski, L. J. Young, and R. L. Hellmich. 2001. Dispersal of adult European corn borer (Lepidoptera: Crambidae) within and proximal to irrigated and non-irrigated corn. J. Econ. Entomol. 94: 1369-1377.

Jones, R. L., W. D. Perkins, and A. N. Sparks. 1975. Heliothis zea: effects of population density and a marker dye in the laboratory. J. Econ. Entomol. 68: 349-350.

Knutson, A. E., and F. M. Davis. 1999. Southwestern corn borer and related stalk borers, pp. 101-104. In K. L. Steffey, M. E. Rice, J. All, D. A. Andow, M. E. Gray, and J. W. Van Duyn (eds.), Handbook of corn insects. Entomological Society of America, Lanham, MD.

Lai, P.-Y., M. Tamashiro, J. K. Fujii, J. R. Yates, and N.-Y. Su. 1983. Sudan Red 7B, a dye marker for Coptotermes formosanus. Proc. Hawaiian Entomol. Soc. 24: 277-282.

Littell, R. C., G. A. Milliken, W. W. Stroup, and R. D. Wolfinger. 1996. SAS system for mixed models. SAS Institute, Cary, NC.

Lloyd, E. P., R. J. Daum, R. E. McLaughlin, F. C. Tingle, G. H. McKibben, J. R. McCoy, M. R. Bell, and T. C. Cleveland. 1968. A red dye to evaluate bait formulations and to mass mark field populations of boll weevils. J. Econ. Entomol. 61: $1440-1444$.

Ng, S. S., F. M. Davis, and J. C. Reese. 1993. Southwestern corn borer (Lepidoptera: Pyralidae) and fall armyworm (Lepidoptera: Noctuidae): comparative developmental biology and food consumption and utilization. J. Econ. Entomol. 86: 394-400.

Ostlie, K. R., G. L. Hein, L. G. Higley, L. V. Kaster, and W. B. Showers. 1984. European corn borer (Lepidoptera: Pyralidae) development, larval survival, and adult vigor on meridic diets containing marker dyes. J. Econ. Entomol. 77: 118-120.

Ostlie, K. R., W. D. Hutchison, and R. L. Hellmich. 1997. Bt-corn and European corn borer. North Central Reg. Ext. Publ. Univ. Minn. Ext. Serv., St Paul, MN

Qureshi, J. A. 2003. Dispersal of marked and feral adult European and southwestern corn borers and its impact on
Bt-corn resistance management. $\mathrm{PhD}$ dissertation, Kansas State University, Manhattan, KS.

Ramaswamy, S. B., R. T. Roush, and W. F. Kitten. 1985. Release and recapture probabilities of laboratory adapted and wild type Heliothis virescens (F.) (Lepidoptera: Noctuidae) in pheromone baited traps. J. Entomol. Sci. 20: $460-464$

Raun, E. S. 1967. Colored European corn borers and eggs from dye containing diets. Proc. N. Central Branch Entomol. Soc. Am. 22: 162-163.

Reynolds, D. R., J. R. Riley, R. J. Armes, N. J. Cooter, M. R. Tucker, and J. Calvin. 1997. Techniques for quantifying insect migration, pp. 111-145. In D. R. Dent, M. P. Walton (eds.), Methods in ecological and agricultural entomology. CAB Int., Cambridge, United Kingdom.

Robertson, J. L., and H. K. Preisler. 1992. Pesticide bioassay with arthropods. CRC Press, Boca Raton, FL.

SAS Institute. 1999-2000. The SAS system for windows, release 8.01. SAS Institute, Cary, NC.

Schroeder, W. J., W. C. Mitchell, and R. Y. Miyabara. 1974. Dye-induced changes in melon fly behavior. Environ. Entomol. 3: 571.

Showers, W. B., R. B. Smelser, A. J. Keaster, F. Whitford, J. F. Robinson, J. D. Lopez, and S. E. Taylor. 1989. Recapture of marked black cutworm (Lepidoptera: Noctuidae) males after long-range transport. Environ. Entomol. 18: $447-458$.

Showers, W. B., R. L. Hellmich, M. E. Derrick-Robinson, and W. H. Hendrix III. 2001. Aggregation and dispersal behavior of marked and released European corn borer (Lepidoptera: Crambidae) adults. Environ. Entomol. 30: $700-710$.

Slansky, F., and J. M. Scriber. 1985. Food consumption and utilization, pp. 87-163. In G. A. Kernt and L. I. Gilbert (eds.), Comprehensive insect physiology, biochemistry and pharmacology, vol. 4. Pergamon, Oxford, England.

Southwood, T.R.E. 1969. Ecological methods with particular reference to the study of insect populations. Methuen and Co. Ltd., London, England.

Steiner, L. F. 1965. A rapid method for identifying dyemarked fruit flies. J. Econ. Entomol. 58: 374-375.

Strand, M. R., B. D. Roitberg, and D. R. Papaj. 1990. Acridine orange: a potentially useful internal marker of $\mathrm{Hy}-$ menoptera and Diptera. J. Kans. Entomol. Soc. 63: 634637.

Throne, J. E., D. K. Weaver, V. Chew, and J. E. Baker. 1995. Probit analysis of correlated data: multiple observations over time at one concentration. J. Econ. Entomol. 88: $1510-1512$.

Waldbauer, G. P. 1968. The consumption and utilization of food by insects. Adv. Insect Physiol. 5: 229-288.

Wilkinson, J. D., R. K. Morrison, and P. K. Peters. 1972. Effect of Calco Oil Red N-1700 dye incorporated into a semiartificial diet of the imported cabbage worm, corn earworm, and cabbage looper. J. Econ. Entomol. 65: 264268.

Received 30 September 2003; accepted 13 January 2004. 